\title{
Diagnosis of the Bio-Compound as an Anti-Fungal from Populus euphratica L. Plant Using Chromatographic Technology
}

\author{
Rana Ibrahim Khaleel \\ College of Engineering, University of Samarra, Samarra, Iraq \\ Email: ranagh83@yahoo.com
}

How to cite this paper: Khaleel, R.I. (2019) Diagnosis of the Bio-Compound as an Anti-Fungal from Populus euphratica L. Plant Using Chromatographic Technology. Open Journal of Ecology, 9, 145-156. https://doi.org/10.4236/oje.2019.95012

Received: January 10, 2019

Accepted: February 1, 2019

Published: May 27, 2019

Copyright (อ 2019 by author(s) and Scientific Research Publishing Inc. This work is licensed under the Creative Commons Attribution International License (CC BY 4.0).

http://creativecommons.org/licenses/by/4.0/

\begin{abstract}
Crude of Plant extracts from materials is necessary screening to determine new biological activities, toxicity and active compounds in bioassay tests. Crude of Populus euphratica L. left is tested to phytochemical screening, constituents, fractionation and MIC technique as anti-fungal. The fractions are subjected to bio-compound analysis using Liquid chromatography-mass spectrometry LC-MS. Phytochemical screening of crude extract shows presence of Glycosides compared with other compounds. While the fraction of ethanolic extract recorded inhibition impact reached (390, mg/L/MIC) agnist type of fungi. Bioassay toxicity using shrimp lethally test $\left(\mathrm{LC}_{50}\right)$ was carried out with the result showing $4.1 \mathrm{mg} / \mathrm{L}$ is low toxic and can be used safely. Alpha Glycoside (4, 6 Benzylidene-1O-Methyl-2O-(2346 Tetra-O-Acetyl-BetadGlucosyl), is a new compound and antifungal action.
\end{abstract}

\section{Keywords}

Populus euphratica, Secondary Metabolites, LC-MS, Antifungi, Alpha Glycoside

\section{Introduction}

The plant kingdom is rich in its secondary products (Tannins), alkaloids (alkali) and other active compounds, which have many therapeutic applications. To find new compounds, it is necessary to screen the crude extract materials to determine new active compounds and to investigate their biological activities. New compounds are generally isolated so that the material (extract) is availed for further isolation of the active compounds and the use of bioassay methods to determine the activity and toxicity of the compounds. Several researchers have 
reported antimicrobial activity of plant derivatives which have potential to meet the requirement for non-hazardous eco-friendly treatments to control post-harvest diseases in citrus. Plant derivatives and their main components possess a wide spectrum of biological activity, and their main advantage being considered generally as safe. Plant derivates contain biocompound that idegradable with low toxic residue. [1] [2] [3] reported that, acetaldehyde compounds bio showed effectiveness against Rhizopus stolonifer causing rot in grapes fruits. Fumigation of apples with acetaldehyde, a natural volatile compound produced in inhibited Penicillium expansum development in the fruits [4] [5]. Antimicrobial biocompounds from plant derivatives mainly comprise glycosides, saponins phenols, alkaloids [6]. Polyphenolics has proved one of the most significant categories of higher plants protective secondary metabolites in disease resistance of plants [7]. The antifungal action of garlic is accredited to allicin (diallyl thiosulfinate), the component of garlic extract which is biologically active [8]. Allicin is formed when the garlic clove is smashed or cut and believed to defend garlic from fungi and parasites of soil [9]. Several researches have studied the inhibitory influence of plant extracts on the growth of mycelia in Aspergillus niger, Penicillium digitatum and Fusarium sp. [10] [11].

The species of Populus euphratica has a very wide range, occurring naturally from North Africa, across the Middle East and Central Asia to western China. It is a prominent component of floodplain ecosystems along river valleys in arid and semi-arid regions. It grows well on land that is seasonally flooded and is tolerant of saline and brackish water [12]. Aim of current study is to identify bioactive antifungal biocompound from extract of Euphrates poplar plant as a natural product.

\section{Methodology}

\subsection{Preparation of Materials for Extraction}

The leaves of plant collected from trees growing at the river side park at Samarra city, Iraq of the mature leaves during the spring season. Fresh materials of each plant were washed under running water in order to get rid of the dirt, insects and plankton. The samples were air dried in the laboratory for seven days under room condition and later in the electric oven for 2 days at $40^{\circ} \mathrm{C}$ [13]. The dried material was then pulverized using a blender (electric mixer) to obtain powder forms of each sample. The powder was collected, and kept in clean and sterile sealed glass jars.

The present study engaged a modification of Wang and Cao [14]. Fifty gram $(50 \mathrm{~g})$ powder obtained from the oven-dried samples of each plant obtained from the oven dried samples was put into $1000 \mathrm{ml}$ glass beaker and treated by drenching with $500 \mathrm{ml}$ of the selected solvent. After the treatment the beakers were covered with aluminum foil and transferred into a water bath $\left(60^{\circ} \mathrm{C}\right)$ and shaken $(100 / \mathrm{min})$ for 5 - 6 hours to get uniform homogenous solutions. Follow- 
ing these treatments, the samples were left overnight in the lab at $27^{\circ} \mathrm{C} \pm 2^{\circ} \mathrm{C}$, and later filtered through two layers of cheese-cloth gauze and Whatman No.2 filter paper. The filtrates were subjected to evaporation using a rotary evaporator at $60^{\circ} \mathrm{C}$ to remove the solvent. The dark spongy materials were dried in an oven at $37^{\circ} \mathrm{C}$ for two days. The dried material was collected and stored in small sterilized screw-capped glass bottles and kept in the refrigerator at $4^{\circ} \mathrm{C}$ for later use.

\subsection{Phytochemical Screening Test for the Extracts}

Crude plant extract was subjected to a phytochemical test using the methods by [15] to test for alkaloids, flavonoids, glycosides, phenols, saponins, steroids, tannins and terpenoids as a preliminary step for diagnosing bioactive compound(s) responsible for anti-fungal activity.

\subsection{Plant Extracts Constituents and Fractionation}

Ethanolic crude extracts of the plant were fractionated with six different solvents ranging from non-polar to polar by using methanol, hexane, ethyl acetate, water, chloroform and acetone as earlier performed by [16], although with some modification in solvent types. The Ethanolic crude extracts (10 gm per samples) were divided between water and hexane $(400 \mathrm{ml}, 1: 1)$ in a superstation funnel. The water layer was further washed with ethyl acetate and acetone $(200 \mathrm{ml}: 200 \mathrm{ml})$. Ethyl acetate and acetone layers were concentrated under a vacuum below $40^{\circ} \mathrm{C}$ to give fractions to ethyl acetate and acetone. Residue from the water soluble layer produced the water fraction. Hexane fraction was further partitioned between $90 \%$ aqueous methanol $(200 \mathrm{ml})$ and chloroform $(200 \mathrm{ml})$. Chloroform and aqueous methanol layers were separately evaporated under a vacuum for the dryness to give the of the soluble residue fractions. Residue from the hexane soluble layer caused the hexane fraction.

The samples were collected in clean and sterile glass bottles $(250 \mathrm{ml})$. After that, the solutions were filtered through two layers of cheese-cloth gauze and Whatman (No. 2) filter paper before the filtrates were subjected to evaporation using a rotary evaporator at $32^{\circ} \mathrm{C}$ to remove the solvents. The dark spongy materials were dried in an oven at $37^{\circ} \mathrm{C}$ for two days. The dry yield of the materials was collected in glass bottles and kept at $4^{\circ} \mathrm{C}$ for $24 /$ hours for further studies.

\subsection{Number of the Compounds in Fractions}

The Rf value or retention factor of each spot was determined by dividing the distance travelled by the product by the total distance travelled by the solvent (the solvent front). These values depend on the type of solvent used to determine the numbers of the compounds for each solvent on the TLC plate. The fractions with similar Rf values were pooled together and labeled accordingly [17]. 


\subsection{Determination of Minimum Inhibitory Concentrations (MIC) and Toxicity}

Fractions that have been collected and developed in TLC were used in the antifungal bioassay of antifungal. A serial (5, 10, 20, 40, 130, 260, 390 and $520 \mathrm{mg} / \mathrm{L})$ Dilution method was applied to determine the MIC of the extracts. Negative control was performed with the DMSO (95.5\%). The Determination of Minimum Inhibitory Concentrations (MIC) was taken as the lowest concentration that prevented fungal growth to determine the antifungal activity of the fractions. $0.1 \mathrm{ml}$ of each of the isolated fungi having a spore suspension (conc. $1 \times$ 106 spores $/ \mathrm{ml}^{-1}$ ) was added by pipette to the centre of the amended PDA extracts. Inoculated plates were incubated at $25^{\circ} \mathrm{C}$ for 7 days. The Petri-dishes inoculated with water served as control. Colony diameter was determined by measuring the average radial growth using a common metric plastic ruler [18]. The inhibition zone was measured using the formula:

$$
\text { Inhibition Zone }=[(\text { Test-control }) / \text { control } \times 100]
$$

Toxicity activity of the bioactive compound(s) from the best fraction following same method was subjected $\mathrm{LC}_{50} .50 \mathrm{mg}$ of Artemia salina (Leach) eggs were added to a $100 \mathrm{~mL}$ conical flask containing $75 \mathrm{~mL}$ sea water. The conical flask was kept in a clean and sterile chamber under room condition for $48 \mathrm{hrs}$ for the eggs to hatch into shrimp larvae. Ten clean and sterile $50 \mathrm{ml}$ conical flasks were used for the BTS evaluation. 20 hatched larvae were added with scapula into each flask containing $45 \mathrm{~mL}$ of sea water. $1 \mathrm{ml}$ of each of the 8 dilutions (640, $320,160,80,40,20,10$ and $5 \mathrm{mg} / \mathrm{L}$ ) was then added with a pipette to each flask and the samples were observed for $48 \mathrm{hr}$ for $50 \%$ mortality of the larvae. The percentage of lethality of the brine shrimp larvae was calculated for each concentration [19] formula as follows:

$$
\% \text { Mortality }=\frac{[(\text { Number of live larvae }- \text { Number of dead larvae })]}{\text { Number of live larvae }} \times 100
$$

The experiment was done in 3 replicate using $\mathrm{CRD}$ and regression analysis for mortality (\%) was performed using Microsoft Excel 2010 (Probity method analysis) following method [20].

\subsection{Liquid Chromatography Analysis}

Tests were carried out in the Centre of Biochemical Research at the School of Pharmacy, University Sains Malaysia (USM). LC analysis was conducted on a LC Perkin-Elmer-Clarus-500 with MS Perkin-Elmer-Clarus-500 [Column: Elite-1, $30.25 \mathrm{~mm} \times 1 \mu \mathrm{mdf}$ under certain conditions which include: a constant flow of $1.3 \mathrm{ml} / \mathrm{min}$; initial inlet temperature of $80^{\circ} \mathrm{C}$ ramped to $280-200^{\circ} \mathrm{C} / \mathrm{min}$ after a 30 seconds delay; an injection volume of $5 \mathrm{ml}$ (LVI) on a Carbofrit plug in the liner with an open purge valve (30:1 split ratio) for 24/seconds and closed for 3.5 minutes and opened again (30:1) until the end of the run; oven temperature program at $75^{\circ} \mathrm{C}$ for $3 \mathrm{mins}$, and $25^{\circ} \mathrm{C} / \mathrm{min}$ ramp to $180^{\circ} \mathrm{C}$ followed by a $5^{\circ} \mathrm{C} / \mathrm{min}$ ramp to $300^{\circ} \mathrm{C}$ and held for 3 mins (total run time: 34.2 mins). 
The mass detector consists of a Turbo mass gold-Perkin Elmer Software with a turbo mass. The MS instrument transfer line temperature was $240^{\circ} \mathrm{C}$ with $230^{\circ} \mathrm{C}$ ion trap and $120^{\circ} \mathrm{C}$ manifold temperatures. The MS Programme utilized was a library used NIST Version-Year 2005. The Inlet line temperature was $200^{\circ} \mathrm{C}$ along with a source temperature of $200^{\circ} \mathrm{C}$. The features of the MS instrument include electron energy of $70 \mathrm{eV}$, mass scan of $45-450 \mathrm{~m} / \mathrm{z}$, and total MS running time of $36 \mathrm{~min}$. The individual constituents showed by GC were identified by comparing their MS with standard compounds of NIST library. The fragmentation data of known compounds were compared with the data available on the library machine and/or online. The molecular weight, molecular formula and composition percentage of the sample material was recorded.

\section{Result and Discussion}

\subsection{Preliminary Phytochemicals Screening}

To determine identity of potential general compounds in crude extract from Populus euphratica L., (Table 1) phytochemical tests were conducted on the ethanol extract and the results presented in Table 1. Qualitative analysis carried out for the ethanol extract of Populus euphratica L. showed the presence of four major groups of phytochemical constituents; glycosides, alkaloids, phenolic and tannins. Further purification and identification of bioactive compound were done using various chromatography and spectrometry methods.

\subsection{Number of the Compounds in Fractions}

The preliminary test of constituent fractions using the Thin Layer Chromatographic (TLC) method was carried out on the extract obtained from ethanolic crude form of Populus euphratica L., in order to determine the best solvent system for separating its various fractions and the best ratio of solvent mixture needed. The retention factors $\left(\mathrm{R}_{\mathrm{f}}\right)$ of the compounds of the crude extract of Populus euphratica L. are shown in Table 1. Result of the TLC profile of the two solvent systems [( 1 1; ethanol; chloroform, benzene ECB $(18 ; 2 ; 2 \mathrm{v} / \mathrm{v}$ for non polar)] and [(S2; Methanol/water/ethyl acetate EMW (10; $1.35 .1 \mathrm{v} / \mathrm{v}$ for polar)]

Table 1. The analysis of phytochemicals in ethanol extract of Populus euphratica L.

\begin{tabular}{cc}
\hline Test & *Extract \\
Steroids & ++ \\
Glycosides & - \\
Terpenoids & - \\
Flavonoids & - \\
Saponins & + \\
Tannins & + \\
Alkaloids & + \\
Phenolic & + \\
\hline
\end{tabular}

${ }^{\star}$ Presence + , High Presence ++ , Absence - . 
under UV illumination, showed that a large compound was present in S1 solvent system, thereby indicating large qualitative and quantitative differences compared to S2. TLC chromatogram of the crude extracts examined under UV light $(254 \mathrm{~nm})$ specifies the profile of compounds extracted by the following solvents; methanol, ethanol, hexane, ethyl acetate, water, chloroform and acetone, resulting to11 compounds in S1 system development of TLC.

The $\mathrm{R}_{\mathrm{f}}$ value, or retention factor, of each spot was determined by dividing the distance traveled by the product by the total distance traveled by the solvent (the solvent front). These values depend on the solvent used to determine the number of compounds for each solvent. The fractions with similar $R_{f}$ values were pooled together and labeled accordingly. The chemical compounds of the plant extracts determined using TLC showed that the ethanol extract recorded higher number of compounds (8) compared to the other solvents used for extraction (S1/EMW). Water and methanol extracts showed only one compound in the solvent system (S1). Ethyl acetate, acetone and chloroform indicated 4 - 5 compounds while hexane showed two compounds only. The retention factors had a wide range for ethanol which was the major compound isolated by solvent (S2). Methanol/water/ethyl acetate EMW recorded 5 compounds. All other solvents recorded less than ethanol with a range of compounds between 2 and 3 as shown in Table 2.

Table 2. Retention factors (compounds) $\left(\mathrm{R}_{\mathrm{f}}\right)$ of fractions extracts from Populus euphratica L. developed in (S1-Ethyl acetateand chloroform) and (S2-Methanol/water/ethyl acetate) solvents system on TLC plate.

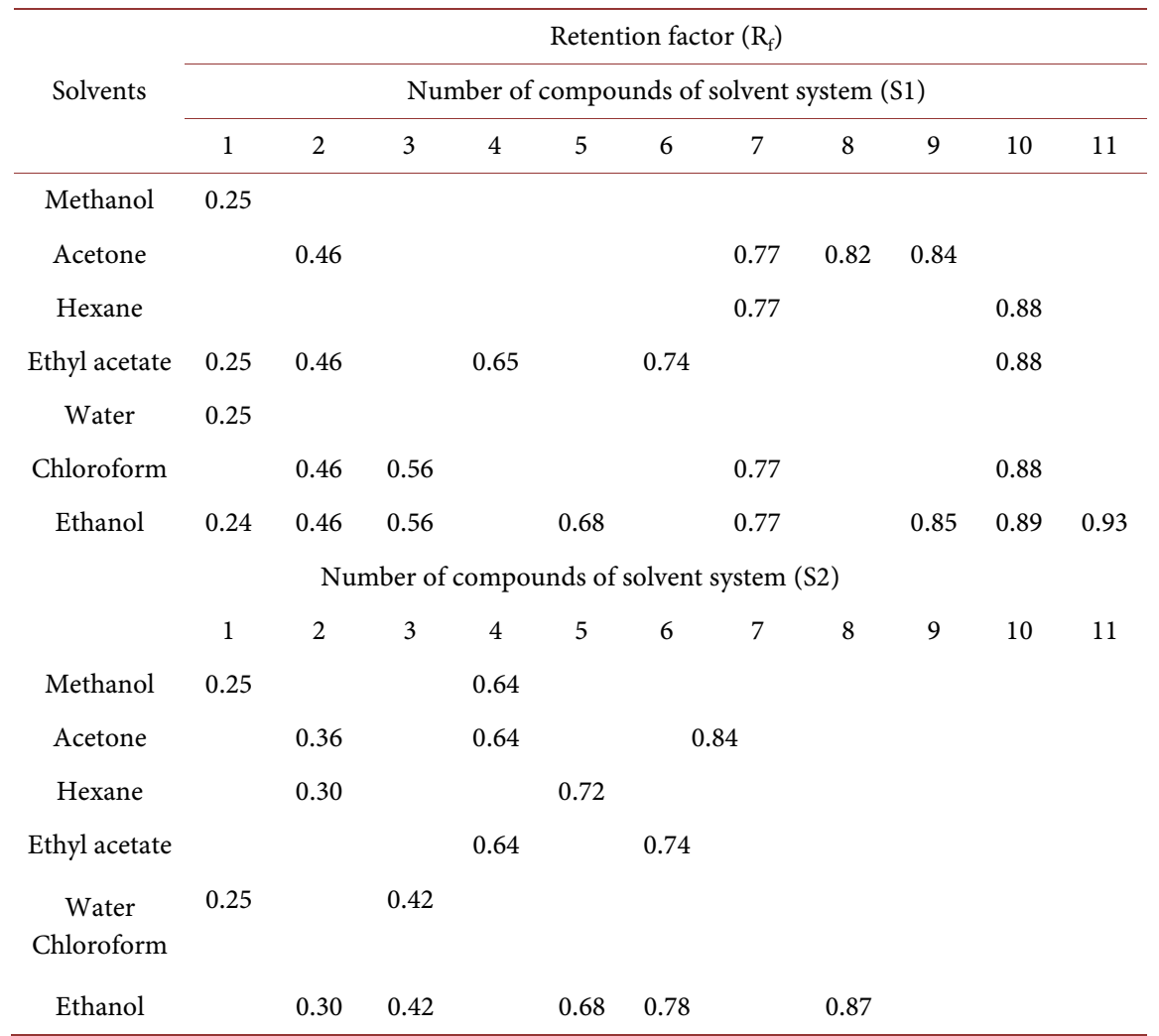


The ethanol extracts recorded significantly higher inhibitory effect compared with other solvents. Ethanol had the highest antifungal activity and gave low MIC for Penicillium digitum, Aspergillus niger and Fusarium sp. (6.25, 12.5 and $12.5 \mathrm{mg} / \mathrm{L}$ respectively), thus making it the best compound with high antifungal activity. In contrast, water, hexane, chloroform and ethyl acetate had the lowest antifungal activity and recorded inhibition values ranging from 50 to $100 \mathrm{mg} / \mathrm{L}$. Furthermore, methanol and acetone showed noteworthy antifungal effects with MIC values reaching $25 \mathrm{mg} / \mathrm{L}$. The variations in the number of fractions in this study could be due to the type of extract, solvent system and technique adopted. Also, difference in the number of compounds between solvent system S1 and S2 may beattributed to the chemical composition of the crude extracts. Ethanol extract reported by [21] yielded nine fractions, which were higher than those in the present study, while [22] isolated 16 fractions of Aloe vera L. using ethanolic solvent in the extraction process. Depending on the best solvent ethanol solvent was selected for next fractions

\subsection{Fractionation of the Ethanol Extracted of Plant Material}

Sixteen fractions were isolated from ethanol extract using Column Chromatography (Silica gel). The fractions were isolated and tested for antifungal activity to determine bioactive (s) compound response to inhibition. One fraction (FC7) obtained from the ethanol extract of Populus euphratica showed maximum antifungal activity against the test organisms with a value of $0.390 \mathrm{mg} / \mathrm{L}$ (Table 3). Fractions: FC1, FC4, FC5, FC9. FC11, FC12 and FC15 recorded weak antifungal activity while the other fractions (FC2, FC3, FC6, FC8, FC10, FC13, FC14 and FC16) showed no activity.

The fraction with maximum antifungal activity from ethanol extract (FC7) showed no variations in inhibition zones against pathogens tested $(\mathrm{P} \leq 0.05)$. Maximum antifungal activity against fungal species, Penicillium digitum, Aspergillus niger and Fusarium sp. recorded 100\% fungal inhibition (Table 4 and Figure 1). Cowan [23], found significant antimicrobial effects of ethanol extracts on leaves of 11 plant species. Among the plant tested, ethanol extract showed the strongest activity against all test microorganisms with the best MIC (4 mg/L). In study of [24] [25] found that ethanol solvent was more efficient than other solvents in extracting phytochemicals from plant materials. In contrast [26] [27] reported that bacteria were not susceptible to ethanol plant extract. Based on results

Table 3. Minimum inhibitory concentration (MIC), of the fractions obtained from the ethanol extracts of Populus euphratica L. using S1 as solvent system by silica gil column chromatography against Penicillium digitum, Aspergillus niger and Fusarium sp.

\begin{tabular}{cccc}
\hline Extract & Fraction No. & MIC (mg/L) & Activity \\
\hline \multirow{3}{*}{ Ethanol } & FC7 & 0.390 & +++ \\
& FC2, FC3, FC6, FC8, FC10, FC13, FC14 and FC16 & N/A & + \\
\hline
\end{tabular}

${ }^{*}+++=$ maximum antibacterial activity, $+=$ Weak activity, $-=$ No activity. 
Table 4. Minimum inhibitory concentration (MIC) and $\left(\mathrm{LC}_{50}\right)$ for two compounds from ethanol extracts of Populus euphratica against Penicillium digitum, Aspergillus niger and Fusarium $s p$.

\begin{tabular}{ccccc}
\hline & Penicillium digitum & Aspergilius niger & Fusarium sp. \\
\hline & \multicolumn{3}{c}{$\mathrm{MIC}(\mathrm{mg} / \mathrm{L})$} & $\mathrm{LC}_{50}(\mu \mathrm{g} / \mathrm{ml})$ \\
\hline FC7-1 & 0.390 & 0.390 & 0.390 & 4.1 \\
FC7-2 & - & - & - & - \\
\hline
\end{tabular}

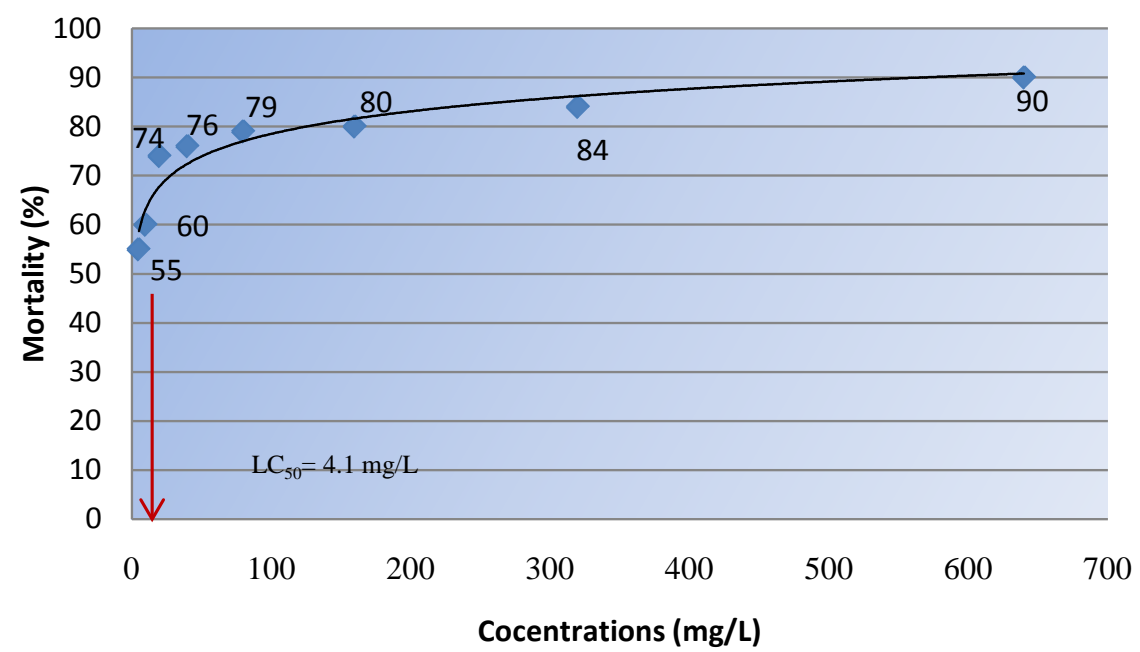

Figure 1. Graphical illustration of $\mathrm{LC}_{50}$ of compound of ethanol Populus euphratica in brine shrimplethality bioassay.

of the study which showed that the ethanol fraction gave a large number compounds (7), a lower MIC ( $3.125 \mathrm{mg} / \mathrm{L})$ was adopted to isolate the active compound. The fraction was subjected to further purification and isolation using column chromatography.

\subsection{Bioassay Antifungal and Toxicity from Active Compound}

Bioassay test were conducted against Penicillium digitum, Aspergillus niger and Fusarium $s p$ for sub fractions FC7-1 and FC7-2. FC7-1 showed very high fungal inhibition activity (100\%) against all pathogens while FC7-2 showed weak any effect on the fungal inhibition zone (Table 4).

In addition, Bioassay toxicity using shrimp lethally test $\left(\mathrm{LC}_{50}\right)$ was carried out (Figure 1), with the result showing $4.1 \mathrm{mg} / \mathrm{L}$. Toxicity category for the plant used in $\mathrm{LC}_{50}$ test was identified based on [28], than $\mathrm{LC}_{50}$ value $2-20 \mathrm{mg} / \mathrm{L}$ is low toxic to humans and animals and can be used safely.

\subsection{Identification of the Anti-Fungi Compounds}

The active compound isolated of the Populus euphratica L. using Liquid Colman Mass Chromatography showed a molecular ion $\mathrm{M}+$ peak at $\mathrm{m} / \mathrm{z}=311$ corresponding to the molecular 535.3276 formula $\mathrm{C}_{30} \mathrm{H}_{8} \mathrm{O}_{8}$ for active biocompound. It was identified as Alpha D-Glycoside (Table 5). 
Table 5. Information active compound isolated from ethanol leaf of Populus euphratica L.

\begin{tabular}{cc}
\hline Product Name & $\begin{array}{c}\text { 4,6BENZYLIDENE-1O-METHYL-2O-(2346TETRA-O-ACETYL-BETAD- } \\
\text { GLUCOSYL) }\end{array}$ \\
\hline Formula & $\mathrm{C}_{30} \mathrm{H}_{48} \mathrm{O}_{8}$ \\
Molecular weight & 536.3276 \\
\hline
\end{tabular}

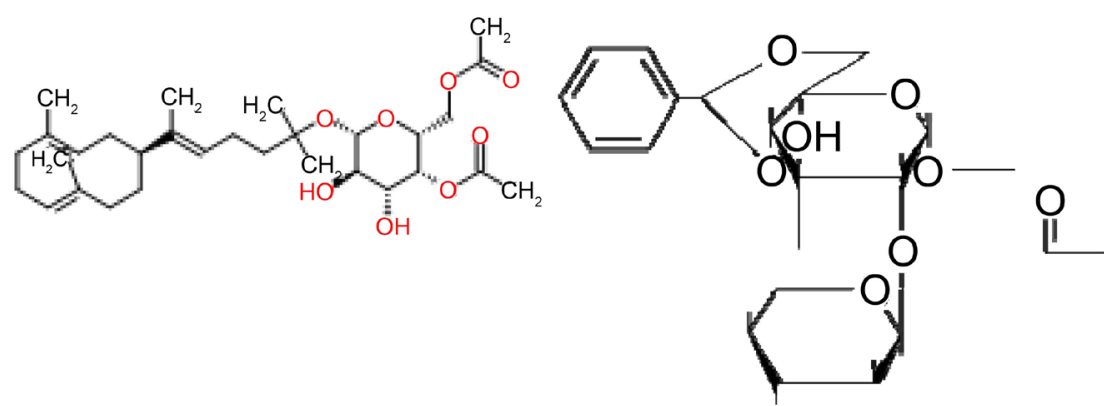

\begin{tabular}{|c|c|c|c|}
\hline SymbolElement & AAtomic weight & Number of atoms & Mass percent \\
\hline Carbon & 12.01078 & 330 & $67.1368 \%$ \\
\hline Hydrogen & 1.007947 & 448 & $9.0146 \%$ \\
\hline Oxygen & 15.99943 & 88 & $23.8486 \%$ \\
\hline
\end{tabular}

Figure 2. Structural, elemental and mass composition (g/mol) of C30H48O8 (FC7-1).

Flavonols glycosides compound isolated from Cerbera manghas from the leaves and fruit, seeds and roots showed a significant level as anti-cancer [29] [27]. Phenylethanoid and phenylpropanoid glycosides are examples of common occurrence in the many plant species. Within the family of Lamiaceae, compounds occur in a number of other genera, including Caryopteris, Eremostachys, Faradaya, Lamium, Leonurus, Marrubium, Prostanthera, Oxera, Scutellaria and Stachys [30]. Antifungal action reported in this study supports previous works [27], which explained that these glycoside compounds (phenylethanoid, forsythoside, verbascoside and styrlpyrone glycosides) isolated from leaves of Phlomis lanceolata L. and Senecio mannii L. (Asteraceae) possessed considerable antifungal and antibacterial characteristics.

Many compounds such as $17 \beta \mathrm{H}$-neriifolin, $14 \beta(\mathrm{H})$ steroid and benzoic acid glycosides were isolated from cerebra species using liquid chromatography (LC-MS) and gas chromatography (GC-MS) techniques as anti-cancer. This data is similar to studies reviewed in the literature [31] [32] [33].

Fragmentation data of compound was compared to the data already available in the library and/or online on the use of LC/UV/MS and LC/MNR for structural identification of natural product (International Laboratory USA, 2012, sigma aldrich Malaysia, 2012 and BiSSC at Multiple Substructure Search). Structural, elemental and mass composition ( $\mathrm{g} / \mathrm{mol}$ ) of $\mathrm{C} 30 \mathrm{H} 48 \mathrm{O} 8$ (FC7-1) expanded in Figure 2.

ALPHA-D-GLUCOSIDE has been isolated from Populus euphratica L has 
potential to be used as an alternative to fungicide. The glucoside biocompound could be studied further mainly on its isolation and characterization for antimicrobial activity in other microbes such as bacteria, virus, and mycoplasma in other disciplines.

\section{Conclusion}

ALPHA-D-GLUCOSIDE has been Characterization of Bioactive Compound as Natural anti-fungal from Populus euphratica. L plant.

\section{Acknowledgements}

I wish to submit my thankful to University of Samarra, Iraq, and in the Centre of Biochemical Research at the School of Pharmacy, University Sains Malaysia (USM) for providing facilities during the stages of completion steps of the research.

\section{Conflicts of Interest}

The author declares no conflicts of interest regarding the publication of this paper.

\section{References}

[1] Roth, U., Friebe, A. and Schnabl, H. (2000) Resistance Induction in Plants by a Brassinosteroid-Containing Extract of Lychnis viscaria L. Festschrift fur Nature forschung Section C-A. Journal of Biosciences, 55, 552-559. https://doi.org/10.1515/znc-2000-7-813

[2] Barkai-Golan, R. (2011) Postharvest Diseases of Fruits and Vegetables Development and Control. Elsevier, Amsterdam.

[3] Avissar, I. and Pesis, E. (1991) The Control of Postharvest Decay in Table Grapes Using Acetaldehyde Vapours. Annals of Applied Biology, 18, 229-237. https://doi.org/10.1111/j.1744-7348.1991.tb06101.x

[4] Narayanasamy, P. (2006) Postharvest Pathogens and Disease Management. John Wiley and Sons, Hoboken, 578 p. https://doi.org/10.1002/0471751987

[5] Neri, F., Mari, M., Meniti, A.M. and Brigati, S. (2006) Activity of Trans-2-Hexenal against Penicillium expansum in "Conference" Pears. Journal of Applied Microbiology, 100, 1186-1193. https://doi.org/10.1111/j.1365-2672.2006.02873.x

[6] Heam, R., Kumaravel, S. and Elanchezhiyan, N. (2009) Antimicrobial Activity of Some of the South-Indian Spices and Herbals against Food Pathogens. Global Journal of Pharmacology, 3, 38-40.

[7] Miron, T., Rabinkov, A., Mirelman, D., Wilchek, M. and Weiner, L. (2000) Mode of Action of Allicin. Biochimica et Biophysica Acta, 1463, 30-30. https://doi.org/10.1016/S0005-2736(99)00174-1

[8] Bowers, J.H. and Locke, J.C. (2004) Effect of Formulated Plant Extracts and Oils on Population Density of Phytophthora nicotianae in Soil and Control of Phytophthora blight in the Greenhouse. Plant Disease, 88, 11-16. https://doi.org/10.1094/PDIS.2004.88.1.11

[9] Ghassan, J., Kanan, R. and Al-Najar, A. (2007) In Vitro Antifungal Activities of 
Various Plant Crude Extracts and Fractions against Citrus Post-Harvest Disease Agent Penicillium digitatum. Jordan Journal of Biological Sciences, 1, 89-99.

[10] Edeoga, H.O., Okwu, D.E. and Mbaebie, B.O. (2005) Phytochemical Constituents of Some Nigeria Medicinal Plants. African Journal of Biotechnology, 4, 685-688. https://doi.org/10.5897/AJB2005.000-3127

[11] Treshkin, S.Y., Kamalov, S.K., Bachiev, A., Mamutov, N., Gladishev, A.I. and Aimbetov, I. (1998) Present Status of the Tugai Forests in the Lower Amu-Dar'ya Basin and Problems of Their Protection and Restoration. In: Ecological Research and Monitoring of the Aral Sea Deltas. A Basis for Restoration, UNESCO Aral Sea Project, 1992-1996 Final Scientific Reports, UNESCO, Paris, 43-53.

[12] Hostettmann, K. (1997) Strategy for the Biological and Chemical Evaluation of Plant Extracts. The International Conference on Biodiversity and Resources, Conservation and Utilization, Phuket, 22-27 November 1997, 1-9.

[13] Francisco, D.H., Francisco Castillo-Reyes, G. and Raul, R. (2010) Lippia graveolens and Carya illinoensis Organic Extracts and There in Vitro Effect against Rhizoctonia Solani Kuhn. American Journal of Agricultural and Biological Science, 5, 380-384. https://doi.org/10.3844/ajabssp.2010.380.384

[14] Wang, G. and Cao, R.L. (1996) Total Antioxidant Capacity of Fruits. Journal of Agricultural and Food Chemistry, 44, 701-705. https://doi.org/10.1021/jf950579y

[15] Pelka, M., Danzl, C., Distler, W. and Petschelt, A. (2000) A New Screening Test for Toxicity Testing of Dental Materials. Journal of Dentistry, 28, 341-345. https://doi.org/10.1016/S0300-5712(00)00007-5

[16] Nguta, J.M., Mbariaa, J.M., Gakuyab, D.W., Gathumbic, P.K., Kabasad, J.D. and Kiama, S.G. (2012) Biological Screening Medicinal Plants Using Artemia salina (Leach). Pharmacology, 2, 458-478.

[17] Okamura, N., Hine, M.N., Harade, S., Fujioka, T., Mihashi, K. and Yagi, A. (1996) Three Chromone Components from Aloe vera Leaves. Phytochemistry, 13, 495-498. https://doi.org/10.1016/0031-9422(96)00306-8

[18] Rubina, L., Piranha, T. and Ebenezer, J. (2009) Isolation Purification and Evaluation of Antibacterial Agents from Aloe vera. Brazilian Journal of Microbiology, 40, 906-915. https://doi.org/10.1590/S1517-83822009000400023

[19] Maher, O., Mohamad, S.M., Al-alawi, E., Al-Zubi, H. and Al-Qudah, J. (2012) Antimicrobial Activity of Crude Extracts of Some Plant Leaves. Research Journal of Microbiology, 7, 59-67. https://doi.org/10.3923/jm.2012.59.67

[20] Eloff, J.N. (1998) Which Extract Should Be Used for the Screening and Isolation of Antimicrobial Components from Plants. Journal of Ethnopharmacology, 60, 1-8. https://doi.org/10.1016/S0378-8741(97)00123-2

[21] Nostro, A., Germano, M.P., D’Angelo, V., Marino, A. and Cannatelli, M.A. (2000) Extraction Methods and Bioautography for Evaluation of Medicinal Plant Antimicrobial Activity. Letters in Applied Microbiology, 30, 379-384.

https://doi.org/10.1046/j.1472-765x.2000.00731.x

[22] Ojala, T., Remes, S., Haansuu, P., Vuorela, H., Haahtela, R.K. and Vuorela, P. (2000) Antimicrobial Activity of Some Coumarin Containing Herbal Plants Growing in Finland. Journal of Ethnopharmacology, 73, 299-305. https://doi.org/10.1016/S0378-8741(00)00279-8

[23] Cowan, M.M. (1999) Plant Products as Antimicrobial Agents. Clinical Microbiology Reviews, 12, 564-582. https://doi.org/10.1128/CMR.12.4.564

[24] (2004) Commercial Vegetable Production Recommendations. The Pennsylvania 
State University. Electronicversion Courtesy of Gerald M. Ghidiu, Rutgers University. http://edis.ifas.ufl.edu/pi008

[25] Chang, L.C., Gillis, J.J., Bhat, K.P.L., Luyengi, L., Farnsworth, N.R., Pezzuto, J.M., et al. (2000) Activity-Guided Isolation of Constituents of Cerbera manghas with Ant Proliferative and Ant Estrogenic Activities. Bioorganic \& Medicinal Chemistry Letters, 10, 2431-2434. https://doi.org/10.1016/S0960-894X(00)00477-7

[26] Cheenpracha, S., Karalai, C., Rat-a-pa, Y., Ponglimanont, C. and Chantrapromma, K. (2004) New Cytotoxic Cardenolide Glycoside from the Seeds of Cerbera manghas. Chemical and Pharmaceutical Bulletin, 152, 1023-1025. https://doi.org/10.1248/cpb.52.1023

[27] Delazar, A., Gibbons, S., Kumarasamy, Y., Nahar, L., Shoeb, M. and Sarker, S.D. (2005) Antioxidant Phenylethanoid Glycosides from the Rhizomes of Eremostachys glabra (Lamiaceae). Biochemical Systematics and Ecology, 33, 87-90.

https://doi.org/10.1016/j.bse.2004.05.011

[28] Jean, C.N., Joseph, T.M., et al. (2007) Styrylpyrone Glycosides with Antimicrobial Activity from Senecio mannii (Asteraceae). Plantas Madicinles, 6, 73-80.

[29] Ahmed, F., Shahid, R. and Sobhan, M.E. (2008) Antibacterial, Cytotoxic and Pharmacological Activities of Cerbera odollam Seeds. Oriental Pharmacy and Experimental Medicine, 8, 323-328. https://doi.org/10.3742/OPEM.2008.8.4.323

[30] Hussain, K., Ismail, Z., Sadikun, A. and Ibrahim, P. (2009) Evaluation of Extracts of Piper sarmentosum for Accelerated Stability by Metabolic Fingerprint Profiling. Pharmacognosy Research, 1, 185-191.

[31] Rouabhi, R., Djebar, H. and Djebar, M.R. (2009) Toxic Effects of Combined Molecule from Novaluron and Diflubenzuron on Paramecium caudatum. American-Eurasian Journal of Toxicological Sciences, 1, 74-80.

[32] Ruch, B. (2001) Processing of Neem for Plant Protection Simple and Sophisticated Standardized Extracts. The Workshop, Neem and Pheromones, Uberaba, 29-30 Augusts 2001, 499.

[33] Zhang, W., Auslane, Mc. and Schuster, D.J. (2004) Repellency of Ginger Oil to Bemisia argentifolii (Homoptera: Aleyrodidae) on Tomato. Journal of Economic Entomology, 97, 1310-1318. https://doi.org/10.1093/jee/97.4.1310 